\title{
Sustentabilidade da dívida pública dos estados brasileiros
}

\author{
Public debt sustainability of brazilian states
}

\author{
Ana Lúcia Fontenele ${ }^{1}$ \\ Francisco José Silva Tabosa \\ José Nilo de Oliveira Júnior ${ }^{3}$ \\ Daniel Barboza Guimarães ${ }^{4}$
}

\section{Resumo}

O objetivo deste estudo é analisar se o endividamento público dos 26 estados brasileiros e do Distrito Federal é sustentável no período de 2000 a 2010, após a implementação da Lei de Responsabilidade Fiscal. Para isso, foi aplicado o teste de raiz unitária de Im, Pesaram e Shin (2003) para dados em painel, o qual considera que os coeficientes autorregressivos podem variar para cada unidade analisada, pois cada estado apresenta características próprias, com o intuito de descobrir se há estacionariedade na razão dívida/PIB. Porém, os resultados mostraram que, exceto para os estados da Região Centro-Oeste, a dívida pública apresentou um comportamento insustentável no período analisado, confirmando os resultados encontrados por Lopes (2007) e Tabosa et al. (2011).

Palavras-chave: Dívida Pública. Sustentabilidade. Estados brasileiros. Lei da Responsabilidade Fiscal.

\section{Abstract}

The aim of this study then is to analyze whether the public debt of the 26 Brazilian states and the Federal District is sustainable in the period 2000-2010, after the

Economista. Mestranda em Economia pela UFAL. Av. Lourival Melo Mota, s/n, Cidade Universitária -Maceió - AL, CEP: 57072-900 - Brasil - E-mail: analucia_fontenele@hotmail.com

2 Economista. Dr. Professor do MAER/UFC. Av. Mister Hull, s/n, Campus do Pici, bloco 826, Fortaleza/CE. CEP 60000-000 - Brasil - E-mail: franzetabosa@ufc.br

3 Economista. Dr. Professor do MAER/UFC. Av. Mister Hull, s/n, Campus do Pici, bloco 826, Fortaleza/CE. CEP 60000-000 - Brasil - E-mail: joseniloojr@yahoo.com.br

4 Economista. Dr. Professor do Departamento de Administração da UFC. Rua Maria Consuelo Freire, 350, Ap 1104 - Cidade dos Funcionários - Fortaleza/CE - CEP: 60824-040 - Brasil E-mail: barbozadan@hotmail.com 
implementation of the Fiscal Responsibility Law. For this, we applied the unit root test of Im, Pesaram e Shin (2003) for panel data, which considers the autoregressive coefficients vary for each unit tested, because each state has specific characteristics, in order to find out if there stationarity in the debt / GDP ratio. However, the results showed that, except for the states of the Midwest Region, public debt presented an unsustainable behavior in the analysis period confirming the results found by Lopes (2007) and Tabosa et al. (2011).

Keywords: Public Debt. Sustainability.Brazilian states.Fiscal Responsibility Law.

\section{Introdução}

A dívida pública, somada à inflação e à taxa de crescimento do Produto Interno Bruto (PIB), consiste em um dos principais problemas para a administração da economia do país (GIAMBIAGI; ALEM, 2002). Por isso, Silva (2009) afirma que a dívida pública pode ainda auxiliar na aplicação das políticas monetárias. A capacidade de pagamento está ligada a políticas fiscal, monetária e cambial críveis. A gestão eficiente do endividamento cumpre papel importante sobre a capacidade de um país absorver choques que podem desestabilizar sua economia e a solidez de suas políticas públicas.

Quando essa dívida se torna insustentável, ou seja, quando o governo não é capaz de pagar a dívida mediante a geração de superávits primários (Receita operacional maior que a despesa operacional), pode prejudicar a estabilidade de preços (SARGENT; WALLACE, 1981), afetar o desempenho da atividade econômica (GONG; GREINER; SEMMLER, 2001), gerar a necessidade de maiores taxas de juros no longo prazo (AFONSO; RAULT, 1997), influenciando de forma negativa o mercado financeiro e as decisões de consumo e investimento dos agentes econômicos.

No Brasil, os anos iniciais da década de 1990 apresentaram um comportamento favorável no que se refere às contas públicas. Já na segunda metade da década, o sucesso do Plano Real na estabilização de preços, depois de seguidas tentativas fracassadas, retornou à situação de desequilíbrio característica dos anos 1980. No entanto, essa 
mesma estrutura que permitiu um endividamento crescente dos estados ao longo dos anos ainda estava presente e ameaçava a continuidade do Plano Real. Para diminuir os gastos estaduais, foram implementados programas de privatizações estatais.

Dessa forma, esperava-se reduzir a capacidade de endividamento autônomo das unidades federativas. Em 1996, o Programa de Incentivo à Redução do Setor Público na Atividade Bancária refinanciou a dívida que os estados detinham com seus bancos públicos. Em 1997, por meio da Lei 9496/1997, ou Lei de Renegociação das Dívidas Estaduais, o governo federal assumiu as dívidas estaduais e financiou seus pagamentos por 30 anos (KHAIR, 2006).

Nesse contexto de desequilíbrio, foi promulgada, em 4 de maio de 2000, a Lei de Responsabilidade Fiscal (LRF), que é uma lei de orçamento equilibrado e tem como objetivo o aumento do controle e transparência dos gastos públicos (GADELHA, 2011). A LRF é a Lei Complementar 101/2000, que atende ao artigo 163 da Constituição Federal. A institucionalidade criada com a LRF definiu regras de controle fiscais mais restritivas do que as que já existiam (PINTO; BIASOTO JR., 2006). Essa lei estabelece uma série de regras a serem seguidas pelos administradores públicos em relação a gastos com pessoal e à dívida pública, as metas fiscais e o controle das finanças em anos eleitorais. A finalidade da Lei é assegurar a sustentabilidade fiscal e a transparência em todos os níveis de governo - esferas municipais, estaduais e União.

Dito isso, o objetivo deste trabalho é analisar o comportamento da dívida pública dos vinte e seis estados e do Distrito Federal após a implementação da Lei de Responsabilidade Fiscal (LRF). Para isso, utilizaram-se dados anuais estaduais da relação dívida pública/PIB e testes de raiz unitária para Dados em Painel, a fim de verificar se a dívida do país é sustentável e identificar a situação atual da dívida dos estados, seguindo a metodologia de Hamilton e Flavin (1986), que foram os pioneiros a investigar a sustentabilidade das dívidas públicas na literatura internacional. 


\section{Revisão de literatura}

O governo acumula dívidas quando insiste na aplicação de uma política fiscal que ocasiona de déficits fiscais contínuos. Essa situação, segundo Luporini (2006), pode levar à insustentabilidade da dívida pública, pois o valor presente da dívida supera os superávits fiscais esperados. Menezes (2006) também comenta sobre os déficits orçamentários contínuos, que para ele, quando ocorrem em qualquer uma das esferas governamentais, afetam aqueles governos que os geram e, além disso, provocam outros efeitos prejudiciais à economia de todo um país.

Quando a restrição orçamentária do governo for satisfeita sem que sejam necessárias rupturas nas políticas monetária e fiscal, então Costa (2009) considera que o endividamento desse país é sustentável. Diz-se que a dívida é considerada sustentável se o valor presente dos superávits futuros for superior ao valor da atual dívida.

Já nos trabalhos do FMI, segundo Camuri (2005), a sustentabilidade é a capacidade do país de pagamento da dívida, podendo recorrer, no futuro, a ajustes das contas, porém, não devem ocorrer mudanças profundas na política econômica utilizada.

Além disso, a avaliação da sustentabilidade da dívida pública fiscal de um país pode ser considerada subjetiva, pois Goldfajn (2002) afirma que é possível escolher trajetórias futuras desfavoráveis para as variáveis: crescimento do PIB, taxa de juros real e taxa de câmbio real, assim como também é possível que as avaliações mais favoráveis ocorram em períodos estáveis.

De acordo com Luporini (2006), a razão dívida/PIB é um dos conceitos de sustentabilidade fiscais mais utilizados para verificar a sustentabilidade da dívida pública. Para o referido autor, o conceito mostra como é importante comparar a taxa de juros real, que é paga sobre títulos do governo, e a taxa de crescimento do produto real do país. 
Uma das abordagens de avaliação da sustentabilidade mais utilizada é testar a estacionariedade da dívida pública (COSTA, 2009). Para ele, uma série é dita estacionária, dado um choque que altere o montante da dívida. Diz-se que a dívida será sustentável se o governo adotar uma política fiscal que faça com que os superávits aumentem até que a dívida retorne ao seu valor.

Um dos trabalhos pioneiros nesse tema é o de Hamilton e Flavin (1986), o qual testa se houve sustentabilidade fiscal nos Estados Unidos no período de 1960 a 1984, por meio de testes de estacionariedade das séries de resultados fiscais e dívida pública.

Entretanto, a metodologia de Hamilton e Flavin (1986) não considera alguns aspectos, dentre os quais está o estoque inicial da dívida. Uma forma de evitar algumas falhas da abordagem anterior é apresentada por Trehan e Walsh (1988), para os quais a restrição orçamentária do governo é satisfeita se as séries de gastos (exclusive o pagamento de juros), receitas e dívida do governo forem cointegradas com vetor de cointegração dado por (1, 1 - r), impondo, portanto, maiores restrições sobre a trajetória do resultado fiscal do que Hamilton e Flavin (1986).

No Brasil, essa metodologia foi usada pela primeira vez por Rocha (1997) e, em seguida, por Issler e Lima (2000), os quais mostraram que a hipótese de estacionariedade para a dívida pública brasileira no período de 1947 a 1992 não pode ser rejeitada. No final desse período analisado, com a Constituição de 1988, houve um crescimento dos gastos públicos e dos déficits nas esferas estaduais e municipais, devido a mudanças nas atribuições de arrecadação e gastos governamentais, que além de dar maior autonomia aos estados não havia regras sobre a captação e utilização das receitas (LEITE, 2006).

Nesse cenário, foi aprovada a Lei de Responsabilidade Fiscal (LRF) que entrou em vigor em maio de 2000. Para Khair (2006), essa lei estabelece normas para orientar as finanças públicas do país. Segundo o autor, as principais vantagens dessa lei foram estimular o orçamento participativo, garantir a transparência da gestão, maior eficiência na 
ação governamental, controlar as despesas, garantir o crescimento das receitas, planejar as ações do governo e impedir a herança fiscal.

Tendo como base as normas de classificação de Inma (1996), Meneses (2006) afirma que essa lei é fraca porque pode haver alteração nas metas de receitas e dos limites de déficits governamentais; para isso, é necessário apenas que seja de interesse de uma maioria do Congresso e que aprovem as alterações.

\subsection{Base de dados}

Este estudo utilizou informações anuais dos vinte e seis estados brasileiros e do Distrito Federal compreendendo o período de 2000 a 2010, referentes ao estoque da dívida líquida do setor público, superávit (ou déficit) primário, receita corrente e despesa corrente disponíveis na Secretaria do Tesouro Nacional (STN). O PIB estadual a preços correntes foi obtido com o IPEADATA, do Instituto de Pesquisa Econômica Aplicada (IPEA), e corrigido pelo INPC com data-base de dezembro de 2012.

Para verificar a sustentabilidade da dívida pública, analisou-se o comportamento da razão entre a dívida líquida do setor público e o PIB de cada Unidade Federal durante o período de 2000 a 2010. A técnica econométrica utilizada foi de dados em painel, contemplando as 27 unidades de análise (as Unidades Federativas - UF) observadas em um período de onze anos, o que totaliza 297 observações.

A seguir, são apresentadas as estatísticas descritivas para a relação dívida/PIB para cada estado das regiões Nordeste, Norte, Centro-Oeste, Sul e Sudeste.

A dívida líquida do setor público da região Nordeste se situa, em média, entre $8,06 \%$ e $38,92 \%$ do PIB. Esses valores se referem aos estados de Rio Grande do Norte e Piauí, respectivamente. Com a média mais elevada da região, o estado do Piauí apresentou uma dívida entre $17,15 \%$ e $81,38 \%$ do PIB, a maior de todo país no período analisado. $O$ estado do Rio Grande do Norte apresentou a menor dívida pública em relação ao PIB, variando entre 5,22\% e 11,08\%. 
Tabela 1 - Estatísticas descritivas da relação dívida/PIB dos estados nordestinos

\begin{tabular}{l|c|c|c|c|c|c|c|c|c}
\hline & \multicolumn{7}{|c}{ Estados } \\
\cline { 2 - 10 } & AL & BA & CE & MA & PB & PE & PI & RN & SE \\
\hline Média & 0.3787 & 0.3038 & 0.1276 & 0.3026 & 0.1648 & 0.3042 & 0.3892 & 0.0806 & 0.1213 \\
\hline Desvio & 0.0418 & 0.1069 & 0.0509 & 0.1389 & 0.0738 & 0.1536 & 0.2121 & 0.0231 & 0.0319 \\
\hline Mínimo & 0.3143 & 0.1702 & 0.0626 & 0.1372 & 0.0766 & 0.1305 & 0.1715 & 0.0522 & 0.0758 \\
\hline Máximo & 0.4435 & 0.4195 & 0.2027 & 0.5327 & 0.3107 & 0.4776 & 0.8138 & 0.1108 & 0.1890 \\
\hline
\end{tabular}

Fonte: Dados da pesquisa. Elaboração dos autores.

Com relação aos estados da região Norte, o estado que apresentou, em média, a maior dívida em proporção do PIB foi o Acre, com 24,54\%; e a menor foi do estado do Amapá, com 7,11\%. Esses valores são baixos se comparados com os da região Nordeste.

Tabela 2 - Estatísticas descritivas da relação dívida/PIB dos estados da região Norte

\begin{tabular}{l|c|c|c|c|c|c|c}
\hline & \multicolumn{7}{|c}{ Estados } \\
\cline { 2 - 8 } & AC & AM & AP & PA & RO & RR & TO \\
\hline Média & 0.2454 & 0.0711 & 0.1182 & 0.0714 & 0.2369 & 0.1660 & 0.1646 \\
\hline Desvio & 0.0891 & 0.0226 & 0.1030 & 0.0142 & 0.0869 & 0.0325 & 0.0742 \\
\hline Mínimo & 0.1553 & 0.0465 & 0.0533 & 0.0502 & 0.1465 & 0.1110 & 0.0669 \\
\hline Máximo & 0.4446 & 0.1059 & 0.3487 & 0.0910 & 0.4125 & 0.2110 & 0.3116 \\
\hline
\end{tabular}

Fonte: Dados da pesquisa. Elaboração dos autores.

De acordo com a Tabela 3, os estados da região Centro-Oeste possuem uma dívida em proporção do PIB oscilando em torno de 5,5\% (Distrito Federal) a 25,89\% (estado do Mato Grosso) em média. O Distrito Federal é a UF do país que apresentou a menor relação de todo o período analisado, uma dívida de apenas 5,5\% em proporção do PIB, variando entre $4,37 \%$ e $6,55 \%$. 
Tabela 3 - Estatísticas descritivas da relação dívida/PIB dos estados da região Centro-Oeste

\begin{tabular}{l|c|c|c|c}
\hline \multirow{2}{*}{} & \multicolumn{4}{|c}{ Estados } \\
\cline { 2 - 5 } Média & DF & GO & MT & MS \\
\hline Desvio & 0.0550 & 0.2407 & 0.2589 & 0.2271 \\
\hline Mínimo & 0.0070 & 0.0736 & 0.0825 & 0.0920 \\
\hline Máximo & 0.0437 & 0.1473 & 0.1179 & 0.1146 \\
\hline
\end{tabular}

Fonte: Dados da pesquisa. Elaboração dos autores.

A região Sul é a que apresenta a menor diferença das médias da relação dívida/PIB entre os seus três estados, com o intervalo de 11, $76 \%$ (Paraná) a 24\% (Rio Grande do Sul), e a maior proporção do PIB no período analisado foi de apenas $35,81 \%$.

Tabela 4 - Estatísticas descritivas da relação dívida/PIB dos estados da região Sul

\begin{tabular}{l|c|c|c}
\hline \multirow{2}{*}{} & \multicolumn{3}{|c}{ Estados } \\
\cline { 2 - 4 } & PR & RS & SC \\
\hline Média & 0.1176 & 0.2400 & 0.1891 \\
\hline Desvio & 0.0433 & 0.0897 & 0.0943 \\
\hline Mínimo & 0.0918 & 0.2249 & 0.1048 \\
\hline Máximo & 0.1404 & 0.2650 & 0.3581 \\
\hline
\end{tabular}

Fonte: Dados da pesquisa. Elaboração dos autores.

A região Sudeste, diferentemente da região Sul, apresenta a maior diferença entre as médias da relação dívida/PIB entre os estados, de 8,4\% (Estado do Espírito santo) a 53,86\% (Rio de Janeiro), como pode ser visto na Tabela 5. 
Tabela 5 - Estatísticas descritivas da relação dívida/PIB dos estados da região Sudeste

\begin{tabular}{l|c|c|c|c}
\hline \multirow{2}{*}{} & \multicolumn{4}{|c}{ Estados } \\
\cline { 2 - 5 } & ES & MG & RJ & SP \\
\hline Média & 0.0840 & 0.2387 & 0.5386 & 0.1876 \\
\hline Ménio & 0.0652 & 0.0405 & 0.1342 & 0.0383 \\
\hline Máximo & 0.0564 & 0.2027 & 0.3455 & 0.1617 \\
\hline
\end{tabular}

Fonte: Dados da pesquisa. Elaboração dos autores.

Para testar a estacionariedade de uma série temporal, o primeiro passo pode ser a análise do comportamento dessa série por meio de gráficos de linha. A seguir, tem-se o Gráfico 1, que apresenta a dívida em proporção do PIB de cada uma das 27 UF, agrupadas por regiões Norte, Nordeste, Sul, Sudeste e Centro-Oeste, para o período de 2000 a 2010.

Gráfico 1 - Dívida/PIB dos estados brasileiros por regiões. 2000-2010
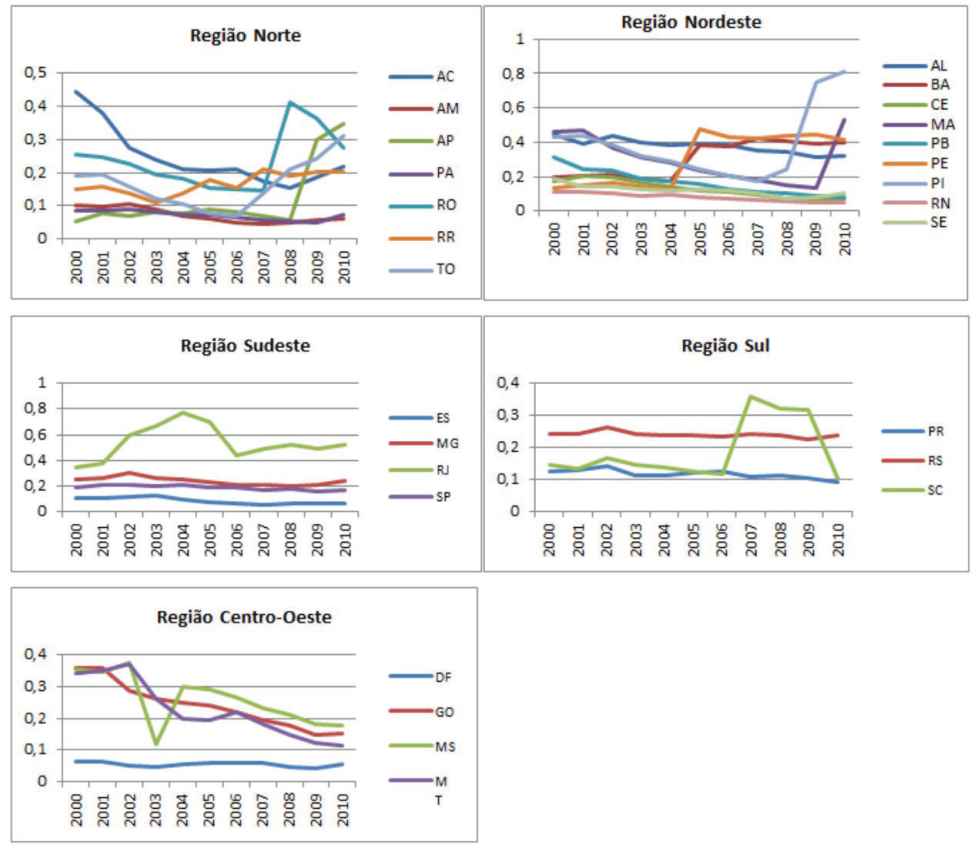

Fonte: Dados da pesquisa. Elaboração dos autores. 
Ao observar o gráfico, percebe-se que o comportamento da relação dívida/PIB de cada estado não segue um padrão ao longo dos anos, apresentando quedas e altas bruscas, o que indica forte possibilidade destas séries serem não estacionárias e, consequentemente, a dívida das UF ser insustentável.

\section{Metodologia}

Com o objetivo de analisar se a dívida pública das 27 UF é sustentável, utilizaram-se dados em painel como método de análise, que é uma técnica constituída a partir da combinação de corte transversal com série de tempo, ou seja, são observações nas mesmas unidades de corte (dados coletados em um determinado ponto no tempo para uma ou mais variáveis) repetidas ao longo do tempo (GUJARATI, 2006). A relação dívida/PIB dos 26 estados brasileiros e do Distrito Federal representa a parte de corte transversal e a série temporal compreende o intervalo de 2000 a 2010. As principais vantagens do uso dessa técnica são: aumentar da eficiência das estimativas e permitir a captação da dinâmica do comportamento das unidades, embora a série de tempo seja curta.

Para verificar a sustentabilidade da dívida pública, deve-se aplicar o teste de raiz unitária, ou seja, testar a estacionariedade da dívida (COSTA, 2009). De acordo com Gujarati (2006), para fazer esse teste para dados em painel, assim como para uma única série, considera-se a seguinte equação:

$$
Y_{i t}=\rho_{i} Y_{i t-1}+X_{i t} \beta_{1}+\varepsilon_{i t}
$$

Em que $X_{i t}$ representa as variáveis explicativas do modelo; $\rho_{i}$, os coeficientes autorregressivos; e $\varepsilon_{i t}$ é o termo de erro. Se $\rho_{i}=1$, diz-se que a série tem raiz unitária, logo, a série em análise é não estacionária.

Existem pressuposições de que o parâmetro $\rho_{i}$ seja comum, ou seja, $\rho_{i}=\rho$, para qualquer unidade de corte, i. Mas também há alguns estudos que consideram que esses parâmetros podem variar para cada unidade. 
$\mathrm{Na}$ segunda abordagem, destacam-se os testes propostos por Im, Pesaram \& Shin (2003). A hipótese nula assume que todas as séries são não-estacionárias, em contrapartida, a hipótese alternativa admite que pelo menos uma série seja estacionária. Esses testes permitem a existência de um processo individual de raiz unitária de forma que os parâmetros de persistência podem variar livremente para cada UF. (MONTEIRO, 2011)

A forma de avaliação de sustentabilidade a ser apresentada tem por essência testar de estacionariedade da dívida pública. Ao recorrer ao teste de raiz unitária e considerar a hipótese nula $\left(\mathrm{H}_{0}\right)$ como sendo dívida não estacionária $(\rho=0)$, se $\mathrm{H}_{0}$ for rejeitada, significa que a dívida está sob controle; caso contrário, a dívida é insustentável.

Este estudo utilizará como metodologia o teste de raiz unitária proposto por Im, Pesaram e Shin (2003), o qual considera que $\rho_{i}$ pode variar livremente para cada unidade i. Esse teste pode ser apresentado da seguinte forma:

$$
\mathrm{Y}_{\mathrm{i}, \mathrm{t}}=\mathrm{n}_{\mathrm{i}}+\mathrm{v}_{\mathrm{t}}+\rho_{\mathrm{i}} \mathrm{Y}_{\mathrm{t}-1}+\phi_{\mathrm{l}, \mathrm{t}}
$$

Em que $\mathrm{i}=1, \ldots, \mathrm{N} ; \mathrm{t}=1, \ldots, \mathrm{T} ; \phi_{\mathrm{i}, \mathrm{t}}=\lambda_{\mathrm{t}}+\xi_{1, \mathrm{t} .}$

O componente $\lambda_{t}$ é chamado de efeito fixo, e para removê-lo, deve ser feita a seguinte transformação:

$$
Y_{i, t}^{*}=Y_{i, t}-\bar{Y}_{t}
$$

Em que $\bar{Y}=\frac{1}{N} \sum_{t=i}^{N} Y_{i, t}$.

O modelo, depois dessa transformação, apresentará a seguinte estrutura:

$$
\Delta Y_{i, t}^{*}=\propto_{i}^{*}+\rho_{i} Y_{i, t}^{*}+\sum_{j=1}^{m_{i}} \theta_{j} \Delta Y_{i, t-1}^{*} \varepsilon_{i, t}^{*}
$$

As hipóteses do teste são:

$$
\begin{aligned}
& \mathrm{H}_{0}: \rho_{1}=\rho_{2}=\ldots=\rho_{N}=\rho=0 \text { (presença de raiz unitária) } \\
& H_{1}: \rho_{1}=\rho_{2}=\ldots=\rho_{N}=\rho<0 \text { (ausência de raiz unitária) }
\end{aligned}
$$


A presença de raiz unitária significa que a série é não estacionária, logo, a dívida é insustentável. $E$ no caso de rejeição da $\mathrm{H}_{0}$, indica ausência de raiz unitária, ou seja, a série é estacionária, o que implica que a dívida é sustentável.

Em seguida, estima-se a equação anterior (i) pelo método dos Mínimos Quadrados Ordinários (MQO) para cada unidade i e calcula-se o grupo médio da estatística t:

$$
\bar{t}_{T N}=\frac{1}{N} \sum_{i=1}^{n} t_{i T}\left(q_{i}\right)
$$

Em que $\mathrm{t}_{\mathrm{i}}\left(\mathrm{q}_{\mathrm{i}}\right)$ é o t-estatístico da $\mathrm{H}_{0}$ da equação $(\mathrm{a})$ e a $\mathrm{E}\left(\mathrm{t}_{\mathrm{T}}\right)=\pi$ e a $\operatorname{Var}\left(\mathrm{t}_{\mathrm{T}}\right)=\sigma^{2}$.

$$
\bar{Z}_{T N}=\left[\left(\sqrt{\frac{1}{N}}\right)\left(\bar{t}_{N T}-a_{N T}\right)\right]\left(\sqrt{b_{N T}}\right)
$$

Agora, calcula-se um grupo médio da estatística t-bar por meio de:

Em que $a_{N T}=\left(\frac{1}{N}\right) \sum_{i=1}^{N} E\left[t_{T}\left(q_{i}\right)\right]$ e $b_{N T}=\left(\frac{1}{N}\right) \sum_{i=1}^{N} \operatorname{Var}\left[t_{T}\left(q_{i}\right)\right]$

Im, Pesarim e Shin (2003) tabularam os valores de e para diferentes defasagens, calculados por simulações de Monte Carlo.

O teste de raiz unitária é aplicado para as variáveis em nível. Se estas não forem estacionárias, forem diferenciadas uma vez e for detectada estacionariedade, diz-se que são integradas de ordem um, I (1), ou seja, a ordem da integração é igual ao número de vezes que a série for diferenciada. Por isso, quando uma série for integrada de ordem superior ou igual a 1, tem-se uma série não estacionária.

\section{Resultados}

Nesta seção, apresentam-se os resultados dos testes de raiz unitária proposto por Im, Pesaram e Shin (2003), os quais consideram que pode variar livremente para cada unidade i, para dados em painel, verificando o comportamento da relação dívida/PIB das UF do país utilizando dados anuais da dívida públicas e do PIB de todos os estados 
brasileiros e do Distrito Federal no período pós-implementação da LRF, de 2000 a 2010.

A Tabela 6 apresenta os principais resultados encontrados do teste de raiz unitária para as variáveis em nível, considerando todos os grupos de estados ou regiões do país. Com um nível de significância de $90 \%$, exceto os estados da Região Centro-Oeste (tanto com Intercepto Individual quanto com Tendência Individual e Intercepto), todos os demais mostraram aceitar a hipótese nula de presença de raiz unitária, indicando que as séries não são estacionárias. Logo, isso implica dizer que as dívidas desses estados não são sustentáveis.

Ao desmembrar o país em conjunto de regiões, os resultados obtidos são semelhantes ao da análise do conjunto de todas as UF do Brasil, exceto os estados da região Centro-Oeste, que apresentaram ser estacionário, indicando que a dívida pública desses estados apresenta ser sustentável. Uma possível explicação para esse resultado está no fato de que as séries dos estados da região Centro-Oeste apresentam os menores desvios padrões entre as demais. Logo, as séries são mais próximas em relação à média. Assim, apresentam ser estacionárias, conforme Hamilton e Flavin (1986).

Tabela 6 - Resultados dos testes de raiz unitária em painel (IPS) para as séries em nível

\begin{tabular}{l|cccc}
\hline Regiões / Estados & \multicolumn{2}{|c}{ Intercepto Individual } & \multicolumn{2}{c}{$\begin{array}{c}\text { Com Tenência Individual e } \\
\text { Intercepto }\end{array}$} \\
& $\begin{array}{l}\text { Estatística } \\
\text { do teste }\end{array}$ & p-valor & $\begin{array}{c}\text { Estatística } \\
\text { do teste }\end{array}$ & p-valor \\
\hline Brasil & $-1,34357$ & 0,1195 & 0,10504 & 0,5418 \\
Norte / Nordeste & $-0,8605$ & 0,1948 & 2,17913 & 0,9853 \\
Centro / Sul / Sudeste & $-1,07553$ & 0,1411 & $-1,4127$ & 0,1061 \\
Norte & $-0,4227$ & 0,3363 & 1,70239 & 0,9557 \\
Nordeste & $-0,77088$ & 0,2204 & 1,39361 & 0,9183 \\
Sul & $-0,36111$ & 0,359 & $-0,77603$ & 0,2189 \\
Centro-Oeste & $-1,5802$ & 0,0570 & $-1,5083$ & 0,0657 \\
Sudeste & 0,11773 & 0,5469 & $-1,23519$ & 0,1756 \\
\hline
\end{tabular}

Fonte: Dados da pesquisa. Elaboração dos autores. 
A Tabela 7, por sua vez, apresenta os valores dos testes de raiz unitária para as variáveis em primeira diferença para todo o país e regiões. Apenas os estados das regiões Norte, Sul e Sudeste apresentaram a presença de raiz unitária. Ou seja, não são estacionárias em primeira diferença.

Tabela 7 - Resultados dos testes de raiz unitária para as variáveis em $1^{\mathrm{a}}$ diferença

\begin{tabular}{l|cccc}
\hline & \multicolumn{2}{|c}{ Intercepto Individual } & \multicolumn{2}{c}{$\begin{array}{c}\text { Com Tendência Individual } \\
\text { e Intercepto }\end{array}$} \\
Regiões / Estados & $\begin{array}{c}\text { Estatística do } \\
\text { teste }\end{array}$ & p- valor & $\begin{array}{c}\text { Estatística } \\
\text { do teste }\end{array}$ & p- valor \\
\hline Brasil & $-5,8602$ & 0,0000 & $-3,3395$ & 0,0004 \\
Norte/ Nordeste & $-2,5551$ & 0,0053 & $-2,2762$ & 0,0066 \\
Centro / Sul / Sudeste & $-6,1408$ & 0,0000 & $-2,2390$ & 0,0126 \\
Norte & $-1,0470$ & 0,1475 & $-0,3602$ & 0,3593 \\
Nordeste & $-2,4574$ & 0,0070 & $-3,1092$ & 0,0009 \\
Sul & $-3,4474$ & 0,0003 & $-1,5974$ & 0,0768 \\
Sudeste & $-3,0112$ & 0,0013 & $-1,8281$ & 0,0566 \\
\hline
\end{tabular}

Fonte: Dados da pesquisa. Elaboração dos autores.

\section{Considerações finais}

Este estudo teve como objetivo analisar a sustentabilidade da dívida pública dos 26 estados brasileiros e do Distrito Federal no período pós-implementação da LRF, de 2000 a 2010, com dados anuais da dívida pública e do PIB de cada uma das UF.

A abordagem empregada, também utilizada por Hamilton e Flavin (1986), consiste em verificar se a relação dívida/PIB é estacionária. Para isso, foi utilizado o teste de raiz unitária proposto por Im, Pesaram e Shin (2003), os quais consideram que o coeficiente autorregressivo pode variar livremente para cada unidade de análise. 
Os resultados obtidos a partir desses testes mostraram que os estados, exceto os da região Centro-Oeste, apresentaram ausência de estacionariedade na relação dívida/PIB do país como um todo. O mesmo comportamento foi observado para o conjunto Norte/Nordeste e Centro/ Sul/Sudeste, e também quando analisado por regiões separadas Norte, Nordeste, Sul e Sudeste, significando, então, que o endividamento público brasileiro é insustentável, ou seja, as UF não conseguirão honrar seus compromissos financeiros sem recorrer a mudanças bruscas na atual política econômica.

Esses resultados são semelhantes aos que foram obtidos por Lopes (2007) e Tabosa et al. (2011), os quais, apesar de utilizarem metodologias diferentes, verificaram que a dívida pública dos estados brasileiros apresentaram ser insustentáveis. Contudo, espera-se que em estudos futuros esses resultados possam ser positivos, e que os governos estaduais consigam contrair dívidas, mas com capacidade de pagamento, com o intuito de torná-la sustentável. Assim, os governos conseguirão mais investimentos em educação, saúde, habitação e infraestrutura.

\section{Referências}

AFONSO, A.; RAULT, C.. What do we really know about fiscal sustainability in the eu? A panel data diagnostic. In: WORKING PAPER SERIES, 820. 2007. European Central Bank. Frankfurt am Main, Alemanha, October, 2007. 56p.

\section{ALBUQUERQUE, C.; MEDEIROS, M.; FEIJÓ, P. H. Gestão de} Finanças Públicas. $2^{\mathrm{a}}$ ed. Brasília (Distrito Federal): Gestão Pública, 2008.

CAMURI, P.A.. Dívida pública, política fiscal e restrição externa no Brasil: 1994-2004. 2005. 88f. Dissertação ( Mestrado em Economia) Universidade federal de Minas Gerais, Belo Horizonte, 2005. 
CAZZARATO, S. Teste de raiz unitária em modelo painel: uma aplicação a teoria de paridade real de juros na América Latina. 2006. 71 p. Dissertação (Mestrado em Economia). Programa de PósGraduação em Economia. Universidade Federal de Santa Catarina, 2006.

COSTA, C.E.L.L. Sustentabilidade da dívida pública. In: SILVA, A. C.; CARVALHO, L. O. de.; MEDEIROS, O.L. de. (Orgs.). Dívida Pública: a experiência brasileira. Brasília: Secretaria do Tesouro Nacional: Banco Mundial, 2009. Cap. 3, p. 81-99.

GADELHA, S.R. de B. Análise dos impactos da Lei da Responsabilidade Fiscal sobre a despesa pessoal e a receita tributária nos municípios brasileiros: um estudo com modelo probit aplicado a dados em painel. Revista Brasileira de Economia de Empresa. Brasília, v. 11, n. 1, p 65-77, jan./jun., 2011.

GOLDFAJN, V. Há Razões para Duvidar de Que a Dívida Pública no Brasil é Sustentável? Notas Técnicas do Banco Central do Brasil, Brasília, n. 25, p. 1-26, jul., 2002. Departamento Econômico (DEPEC) GONG, G.; GREINER, A.; SEMMLER, W. Growth Effects of Fiscal Policy and Debt Sustainability in the EU. Empirica, [s.I], v. 28, n. 1, p 3-19, March, 2001.

GUJARATI, D. N. Econometria Básica. Tradução de Maria José Cyhlar Monteiroda 4. ed.americana. Rio de Janeiro: Elsevier, 2006. .

HAMILTON, J. D. \& FLAVIN, M. A. On the limitations of government borrowing: a framework for empirical testing. American Economic Review, Nashville, v.76, n 4, p. 808-819, Sept. 1986.

IM, K.S.; PESARAM, M. H.; SHIN, Y.. Testing for Unit Roots in Heterogeneous Panels. Journal of Econometrics, [s.I], v. 115, n. 1, p. 53-74, july, 2003.

KHAIR, A. A.. A questão fiscal e a Lei da Responsabilidade Fiscal. In: PINTO, M.P.A. e BIASOTO JÚNIOR, G. (Orgs). Política fiscal e 
desenvolvimento no Brasil. Campinas, São Paulo: UNICAMP, 2006. Cap. 12, p. 343-370.

LEITE, M.G. Economia política das finanças subnacionais: teoria e análise empírica para os estados brasileiros e Distrito Federal na década de 1990. 2005. 117f. Tese (Doutorado em Economia de Empresas). - Escola de Administação de Empresas de São Paulo, Fundação Getúlio Vargas, São Paulo, 2005.

LOPES, D. T. Função de reação da política fiscal e intolerância da dívida: o caso brasileiro no período pós-real. 2007. 64 p. Dissertação (Mestrado em Economia). - Faculdade de Economia, Administração e Contabilidade. Ribeirão Preto, Universiade de São Paulo (USP). 2007.

LUPORINI, V. Uma nota sobre inflação, déficits e a sustentabilidade da dívida governamental. Economia e Sociedade, Campinas, v. 13, n. 2 (23), p. 175-184, jul./dez. 2004.

MENEZES, R. T de. Impactos da Lei da Responsabilidade Fiscal sobre os componentes de despesas dos municípios brasileiros. Brasília: ESAF, 2005. 64 p. Monografia premiada em $1^{\circ}$ lugar no $X$ Prêmio Tesouro Nacional, 2005. Lei de Responsabilidade Fiscal, Brasília (DF),

MONTEIRO, V.B. Crescimento e infraestrutura: três ensaios com dados em painel. 2011. 72 p. Tese (Doutorado em Economia). Programa de Pós-Graduação em Economia, Universidade Federal do Ceará, Fortleza, 2011.

PEREIRA, J.G.M.A. Sustentabilidade da dívida pública dos estados brasileiros. 2008, 89f. Dissertação (Mestrado em Economia) Centro de Desenvolvimento e Planejamento Regional (CEDEPLAR), Faculdade de Ciências Econômicas, Belo Horizonte, MG, 2008.

PINTO, M.P.A.; BIASOTO JÚNIOR, G. (Orgs). Política fiscal e desenvolvimento no Brasil. Campinas, São Paulo: UNICAMP, 2006. 
PINTON, O.V.F. e MENDONÇA, H. de F. Impulso Fiscal e Sustentabilidade da Dívida Pública: uma análise da política fiscal brasileira. Economia \& Tecnologia, [s.I], ano 05, v. 17, p. 17-26, abr./ jun., 2009

SARGENT, T. J.; WALLACE, N. Some unpleasant monetarist arithmetic. Federal Reserve Bank of Minneapolis Quaterly Review, [s.I], v. 5, n.3, p. 1-17, Fall, 1981.

SILVA, A.C.; CARVALHO, L.O. de.; MEDEIROS, O.L. de. (Orgs.)

Dívida Pública: a experiência brasileira. Brasília: Secretaria do Tesouro Nacional: Banco Mundial, 2009.

TABOSA, F.J. ; FERREIRA, R. T. ; SIMONASSI, A. G.. Reação Fiscal ao Aumento da Dívida Pública: Uma Análise para os Estados Brasileiros. In: Encontro Nacional de Economia da ANPEC, 39., 2011, Foz do Iguaçu/PR. Anais... Foz do Iguaçu/PR: Encontro Nacional de Economia da ANPEC, 2011. p 1-18.

Artigo recebido em: 27/07/2015

Aprovado em: 21/09/2015 